\title{
Corrosion Behavior of Carbon Nanotubes/Polyurea Composite Coatings in Alkaline Environment
}

\author{
Jiaao Yan, Zhiming Gao*, Jian Song, Zhihong Liu, Qingchao Tan \\ School of Material Science and Technology, Tianjin University, Tianjin, 300350, China \\ "E-mail: gaozhiming@tju.edu.cn
}

doi: $10.20964 / 2020.03 .45$

Received: 22 October 2019 / Accepted: 13 January 2020 / Published: 31 August 2020

\begin{abstract}
The carbon nanotubes (CNTs) were doped into polyurea for the test of Shore hardness and the adhesion on the aluminum alloy substrate. The corrosion resistance of carbon nanotube/polyurea composite coatings was investigated by electrochemical impedance spectroscopy (EIS) in $0.1 \mathrm{~mol} / \mathrm{L} \mathrm{NaOH}$ solution for 21 days. The results showed that the surface hardness of polyurea was significantly improved after doping with CNTs while the adhesion to aluminum alloy substrate was slightly improved. The coating equivalent capacitance $(\mathrm{Rc})$ and charge transfer resistance $(\mathrm{Rct})$ of the polyurea coating added with CNTs were larger than the pure polyurea coating during immersion, indicating that adding CNTs can provide better protection to the aluminum alloy substrate. The relationship between the doping amount of carbon nanotubes and corrosion resistance is $1.0 \mathrm{wt} . \%>0.5 \mathrm{wt} . \%>0 \mathrm{wt} . \%$.
\end{abstract}

Keywords: polyurea, carbon nanotubes, adhesion, EIS, corrosion resistance

\section{$\underline{\text { FULL TEXT }}$}

(C) 2020 The Authors. Published by ESG (www.electrochemsci.org). This article is an open access article distributed under the terms and conditions of the Creative Commons Attribution license (http://creativecommons.org/licenses/by/4.0/). 